\title{
Sociodemographic Characteristics and Lifetime Drug Use of the Jamaican Adult Prison Population G Mitchell ${ }^{1}$, W Abel $^{2}$, P Clarke ${ }^{3}$, U Atkinson ${ }^{4}$, P Whitehorne-Smith ${ }^{2}$
}

\begin{abstract}
Objective: To explore the socio-demographic profile of the Jamaican prison population.

Method: This was a descriptive cross-sectional study that utilized a survey design. The survey included a proportional random sample from seven prisons across the island. The survey questionnaire was interviewer administered by a team of trained interviewers. The survey was based on the Inter-American Uniform Drug Use System (SIDUC) questionnaire. Participation was voluntary.

Results: 647 inmates participated in the study. The respondents were divided into two groups: those on remand, and those that were convicted. Among both categories more males were incarcerated than females. The mean age of convicted respondents was 37.17 years (s.d.+/-11.417). The mean age of remanded respondents was 30.13 years (s.d.+/-8.809). Most inmates were single and reported being self-employed prior to incarceration. Most inmates reported a lifetime use of alcohol, marijuana or tobacco, with marijuana use having the earliest average age of initiation, 15 years. The initiation age range for all three was between the ages of 15 and 17 years. A link was also found between robbery and a lifetime prevalence of marijuana as well as stealing and a lifetime prevalence of crack use. Lifetime prevalence of cocaine use was also significantly associated with recidivism rates among convicted inmates.
\end{abstract}

Conclusion: The findings of this survey are consistent with international literature. This study provides crucial insight about the interaction and overlapping of the socio-demographic factors that influence the Jamaican prison system.

Keywords: Drug use, Jamaica, prison

From: ${ }^{1}$ MSc Psychology Candidate, Leeds Beckett University, UK, ${ }^{2}$ Section of Psychiatry, Department of Community Health \& Psychiatry, University of the West Indies Mona, Jamaica ${ }^{3}$ National Council on Drug Abuse, 2-6 Melmac Avenue, Kingston, Jamaica, ${ }^{4}$ Inter-American Drug Abuse Control Commission (CICAD), Washington DC, USA.

Correspondence: Mrs P Whitehorne-Smith, Department of Community Health and Psychiatry University of the West Indies, Kingston 7, Email: patrice.whitehorne@yahoo.com 


\section{INTRODUCTION}

Globally, prison systems have reported an increase in inmate populations ${ }^{1}$. Walmsley reported in his 2013 World Population Study that the countries with the highest reported incarceration rates, (top 50) include the United States and most Latin American countries(1). Most Latin American countries have seen at least a $40 \%$ increase since the start of the $21^{\text {st }}$ century, while Colombia, Mexico, Argentina and the United States have experienced a prison population growth that varies from about $60 \%$ to $85 \%(2)$.

According to a 2012 comparative analysis of inmates in 4 countries that was done by the Inter-American Drug Abuse Control Commission (CICAD)(3), the age range of those incarcerated in the Caribbean countries studied, was between 25 - 35 years of age, with the majority of those inmates being in their early thirties. In a similar 2013 study done in the UK the 30-39 age range was the most populous (4). Those incarcerated are young men of working age (4).

With regards to employment and education levels, the CICAD analysis reported that the inmates who were employed prior to incarceration were either employed full time or selfemployed. Berman and Dar's study states that only one third of the inmate population reported being employed within four weeks of being in police custody. With regards to education levels, Berman and Dar also report that $47 \%$ of the prison population study held no formal academic qualifications, with approximately $5 \%$ of the inmate population having ALevels(4).

Recidivism rates were also reported to be high in all countries included in the CICAD analysis (3). The CICAD analysis also reports that the average rate of recidivism for repeat offenders was $49.8 \%$ across the four countries surveyed, while the average for first time offenders was reported to be $50.3 \%$ (2). On the other hand, the rate of re-offence for 
deportees is relatively low when compared to the rate of recidivism of inmates released from local prisons in Trinidad and Tobago and Barbados as evidenced in a report by the United Nations Office on Drugs and Crime and the Latin America and the Caribbean Region of the World Bank(2). However, in the same study, it was cited that deportees who have been away from Jamaica for an extended period of time are at a higher risk for re-offence upon their return home (3).

In a study done in the Grenadian prison system, it was found that among first time offenders, $25 \%$ of offences were committed under the influence of drugs, while $33 \%$ of repeat offenders committed offences under the influence of drugs, with alcohol (13\%) and marijuana (6\%) having the highest percentages of use (5). The crimes that most commonly occurred under the influence of drugs were sexual and physical assault and malicious damage (5). The crime that was committed least while under the influence of drugs was capital crime. It should be noted that this reported stated that all crimes committed by unemployed respondents occurred under the influence of drugs. Furthermore, those inmates with only primary level education committed drug related crimes more often than those with a secondary school education. Inmates also reported that family members' main drug choices were marijuana, alcohol and tobacco (5).

The present study sought to explore the sociodemographic and lifetime drug use practices of the Jamaican prison population.

\section{SUBJECTS AND METHODS}

This was a descriptive cross sectional study which utilized a survey design. The survey included a proportional random sample of inmates from seven adult correctional institutions across the island. For the purposes of this study "on remand" is defined as those persons who 
have been accused of a crime and who are awaiting trial based on the judicial investigative process. "Convicted" is defined as those persons who have received a sentence ruling with regard to due process and a related trial and who are serving a sentence.

Convicted and remanded inmates 18 and older were randomly selected from lists provided - by each institution. Mentally ill persons were excluded from the selection process. The survey questionnaire was based on the Inter- American Uniform Drug Use System (SIDUC) questionnaire. This was an interviewer-administered questionnaire which captured information related to socio-demographic characteristics, criminal history and personal drug history among other issues.

Participation in the study was voluntary and interviews were conducted by a team of trained interviewers. Ethical procedures of anonymity and confidentiality were observed by excluding all identifiable information from the questionnaires.

Data analysis

Data were entered and cleaned by trained data entry clerks using the Statistical Package for Social Sciences (SPSS), Descriptive statistics were performed on key variables and the level of significance utilized was $\mathrm{p} \leq 0.05$.

\section{RESULTS}

A total of 647 inmates took part in the study. Among the convicted sample $(\mathrm{N}=554), 88.8 \%$ were males and $11.2 \%$ were females. The mean age of respondents was 37.17 years (s.d. +/11.417). Among the remanded sample $(\mathrm{N}=93), 81.7 \%$ were males and $18.3 \%$ were females. The mean age of respondents was 30.13 years (s.d. +/-8.809). 
Most inmates were single $(64.1 \%$ of the convicted inmates and $62.4 \%$ of the remanded inmates). Also a notable number of inmates reported their employment as 'informal activity '(self employed) prior to entering prison (see Table 1).

As it relates to the education level of inmates approximately half of those who were convicted or on remand had an 'incomplete secondary school' level of education (Figure1).

\section{Offending pattern}

Most of the inmates reported that this was their first term of imprisonment ( $73 \%$ convicted and $64 \%$ remanded). For the convicted group, the mean age of first offence was 26.77 years and those on remand 25.30 years.

\section{Repeat offending}

The length of sentences ranged from 1-2250 months, however the mean length of sentences was 148.68 months (s.d. +/-194.677). Also the age of first offence that they were charged or sentenced for ranged between 8-71years with the mean age being 26.77 years (s.d.+/-9.709). More than $10 \%$ of convicted inmates $(\mathrm{N}=35)$ reported that they had been previously imprisoned in a youth detention centre because they were a minor $(15.7 \%)$.

Approximately a quarter of convicted inmates $(24.4 \%, \mathrm{n}=127)$ reported that their family members had a history of involvement in criminal activity.

For the remanded inmates, approximately $36 \%$ reported that they had been in prison between 1-10 other times. Remanded inmates reported that incarceration for their current alleged crime ranged between 1-110 months with the mean time being 23.50 months (s.d.+/19.372). Also the age of first offence that they were charged or sentenced for ranged between 12-52 years with the mean age being 25.30 years (s.d. +/-9.577).

More than half of the remanded inmates (55.9\%) reported that there was no previous offence for which they were accused or sentenced, while $44.1 \%$ reported being accused or sentenced for other offences'. These included murder, shooting, wounding, and illegal 
possession of a firearm, extortion, possession of marijuana, robbery, larceny and receiving stolen goods. Only $15 \%$ of remanded inmates reported being detained in a youth detention centre because they were a minor.

A significant number of inmates reported that their family members were involved in criminal activities $(28.1 \%)$. The family members identified as being involved were: other (42.9\%), uncle (21.4\%), brother (7.5\%), and mother (3.6\%).

Drug use prior to imprisonment

The majority of inmates reported that they had used alcohol, marijuana and tobacco at some point in their lives (Table 2). Lifetime prevalence of alcohol use was reported at $78.3 \%$ among convicted inmates and $80.4 \%$ among remanded inmates with the mean age of first use - being reported as 15.87 years (s.d. +/- 4.462).

Similarly, the lifetime prevalence of marijuana use was reported at $75.4 \%$ among convicted inmates and $79.6 \%$ among remanded inmates. The mean age of first use of marijuana was 15.08 years (s.d. +/- 3.849).

The lifetime use of tobacco was also high among both convicted and remanded inmates with $68.5 \%$ of convicted inmates and $74.2 \%$ of remanded inmates reporting lifetime use. The mean age of first use of tobacco was 15.94 years (s.d.+/-5.319).

A small proportion of convicted inmates reported cocaine, crack, heroin, inhalant and medication (without prescription) use while no remanded inmates reported the use of these substances.

Repeat offending and lifetime prevalence of drug use

Fisher's exact test showed no significant differences in substance use rates between first time and repeat offenders. The same results were obtained when convicted and remanded inmates were compared $(\mathrm{p}>0.05)$.

Offence category and Lifetime prevalence of drug use 
Fisher's exact test and Chi square analysis revealed significant differences between:

Robbery and lifetime prevalence of marijuana use $(\mathrm{p}=0.037, \mathrm{p}<0.05)$; with significantly more inmates who reported marijuana use being convicted for robbery $(14.5 \%)$ than those who did not report marijuana use $(7.5 \%)$.

Stealing and lifetime prevalence of crack use $(\mathrm{p}=0.025, \mathrm{p}<0.05)$; with significantly more inmates who reported crack use being convicted for robbery $(22.2 \%)$ than those who did not report crack use (3.9\%).

When means were compared using Independent sample T test, it was found that only lifetime prevalence of cocaine use was significantly associated with number of times in prison among convicted prisoners $(\mathrm{p}=0.000)$ with those who used cocaine showing a significantly higher mean $(m=5.43, \mathrm{~s} . \mathrm{d}+/-6.503)$ for number of times in prison than those who did not report using cocaine use (m=2.35 s.d. +/-1.317).

\section{DISCUSSION}

The sociodemographic findings of the study showed that more males than females were convicted and remanded for criminal offences. This finding is constant with international literature which denotes that males tend to engage in criminal activity at a higher rate than females (6).

Consistent with findings from the CICAD 2012 report conducted in four other Caribbean countries is the finding that age group most represented among the inmate population was 25-35 years. Also of note is that the majority of the inmates reported being single and a significant number reported having incomplete secondary level education.

This was perhaps tied to their reports of 'informal activity' (self-employment) as their employment status prior to being incarcerated. This finding is not surprising as several 
researchers have found a clear link between dropping out of school and criminal behaviour and faring poorly in the formal labour market $(7,8)$. The lack of formal education tends to diminish a person's employability and may result in informal methods of earning.

Most of the convicted and remanded inmates were first time inmates; but a significant number were repeat offenders which were in line with CICAD report (3).

In terms of drug use, the vast majority of inmates reported lifetime use of alcohol, marijuana and tobacco. Marijuana had the earliest average age of initiation of all the drugs, with both convicted and remanded inmates reporting starting use as early as 15 years. The approximate average age of initiation of alcohol use was 16 years among convicted and 15 years among remanded inmates. For tobacco use the average age of initiation was 17 years among convicted inmates and late 15 years among remanded inmates.

Interestingly, these findings are consistent with findings from the National Secondary School Survey which found a clear pattern of increased risk of drug use among students between the ages of 15-16 years (9). In addition, the finding that marijuana was usually the first drug of initiation is in line with the findings of CICAD 2012 study.

Also of importance is the associations identified between lifetime prevalence of marijuana use and robbery and lifetime prevalence of crack/cocaine and stealing as criminal offences. Additionally, lifetime prevalence of cocaine use was significantly associated with the number of times in prison among convicted prisoners. This is likely to be linked to drug seeking behaviour of the inmates which contributed to criminal behaviour.

There were a few key limitations of the study which are considered important to note. This study was exploratory in nature and was not indeed to speculate on causation. It focused only on individuals currently incarcerated (whether convicted or remanded). Additionally, in one institution on the day of data collection there was significant difficulty accessing the preselected participants as such a more convenient sample was utilized to gather the data. This 
may be a notable limitation to the generalizability of these findings. Another limit to this study is the focus on lifetime prevalence of substance use which though useful, is often times not the best correlate for certain outcomes.

\section{CONCLUSION}

This exploratory study among prisoners has provided critical insights into key areas of sociodemographic profiles, drug use patterns, and criminal history. Many other factors such as psychological, socio-cultural and economic factors play a major part in criminality and oftentimes these factors are overlapping in their influence on individuals' actions.

\section{ACKNOWLEDGEMENTS}

The authors wish to express thanks to the National Council on Drug Abuse for allowing access to their data for the publication as well as the Inter-American Drug Abuse Control Commission (CICAD) for providing the funding for the broader research conducted on the relationship between drugs and crime in Jamaica. 


\section{REFERENCES}

1. Walmsley, Roy. World Prison population list (tenth edition). International Centre for Prison Studies. London, 2013. Web. 10 Jun. 2015.

2. Crime, Violence, and Development: Trends, Costs and Policy Options in the Caribbean, (Report No. 37820). The United Nations Office on Drugs and Crime and the Latin America and the Caribbean Region of the World Bank March 2007. Web. 10 Jun. 2015.

3. Organization of American States/CICAD. Exploring the Relationship between Drugs and Crime: A Comparative Analysis of Survey Data from Prisoners in Four Caribbean Countries. Washington DC; 2012. Web. 20 Jun. 2015.

4. Berman, Gavin and Dar, Aliyah. Prison Population Statistics. Ministry of Justice in England \& Wales. England, 2013. Web. 20 Jun. 2015.

5. Crawford-Daniel, Wendy and Alexis, Jicinta. Linkages between Drugs and Crime among Inmates at Her Majesty's Prison (PowerPoint presentation). Grenada, 2010. Web. 20 June 2015.

6. Lanctot, Nadine and LeBlanc, Marc. Explaining deviance by adolescent females. In M. Tonry (Ed.) Crime and Justice, vol. 29.Chicago: University of Chicago Press, 2002. 113-202. Print.

7. Belfield Clive, and Levin Henry. The economic losses from high school dropouts in California. California Dropout Research Project Report \#1. California, 2007. Web. 12 Jan. 2015.

8. Bjerk, David. Re-examining the impact of dropping out on criminal and labour outcomes in Early Adulthood. Discussion series, IZA. Germany, 2011. Web. 12 Jan. 2015. 
9. National Council on Drug Abuse (2014). National Secondary School Survey report. NCDA library, 2013. Print. 
Table 1: Sociodemographic characteristics of respondents

\begin{tabular}{|c|c|c|c|c|}
\hline & \multicolumn{2}{|c|}{ Convicted } & \multicolumn{2}{|c|}{ Remand } \\
\hline & $\begin{array}{l}\text { Frequency } \\
\text { (f) }\end{array}$ & $\begin{array}{l}\text { Percent } \\
\%\end{array}$ & Frequency (f) & Percent $\%$ \\
\hline \multicolumn{5}{|l|}{ Gender } \\
\hline Male & 492 & 88.8 & 76 & 81.7 \\
\hline Female & 62 & 11.2 & 17 & 18.3 \\
\hline \multicolumn{5}{|l|}{ Age Group } \\
\hline $16-24$ & 63 & 11.4 & 31 & 33.3 \\
\hline $25-35$ & 211 & 38.3 & 41 & 44.1 \\
\hline $36-45$ & 159 & 28.9 & 12 & 12.9 \\
\hline $46-54$ & 70 & 12.7 & 8 & 8.6 \\
\hline $55-65$ & 38 & 6.9 & 1 & 1.1 \\
\hline$>65$ & 10 & 1.8 & 0 & 0 \\
\hline Status: Convicted/Remand & 554 & 85.6 & 93 & 14.4 \\
\hline \multicolumn{5}{|l|}{ Marital status } \\
\hline single & 355 & 64.1 & 58 & 62.4 \\
\hline married & 35 & 6.3 & 8 & 8.6 \\
\hline widowed & 7 & 1.3 & 0 & 0 \\
\hline divorced & 10 & 1.8 & & 0 \\
\hline common law relationship & 85 & 15.3 & 0 & 12.9 \\
\hline separated & 9 & 1.6 & 1 & 1.1 \\
\hline visiting relationship & 52 & 9.4 & 14 & 15 \\
\hline Don’t know & 1 & .2 & 0 & 0 \\
\hline \multicolumn{5}{|l|}{$\begin{array}{l}\text { Pre-imprisonment } \\
\text { employment }\end{array}$} \\
\hline Unemployed & 41 & 7.4 & 13 & 14 \\
\hline part time employee & 77 & 13.9 & 11 & 11.8 \\
\hline full time employee & 156 & 28.2 & 25 & 26.9 \\
\hline informal activity (self & 264 & 47.7 & & \\
\hline employed) & & & 42 & 45.2 \\
\hline other & 16 & 2.9 & 2 & 2.2 \\
\hline
\end{tabular}


Table 2: Lifetime prevalence of drug use and age of first use among convicted/remanded inmates

\begin{tabular}{|c|c|c|c|c|c|}
\hline \multirow[b]{2}{*}{ Drug Use } & \multicolumn{2}{|c|}{ Lifetime Use (\%) } & \multicolumn{3}{|c|}{ Age of First Use (yrs.) } \\
\hline & Convicted & Remand & Convicted & Remand & \\
\hline & & & 15.17 (s.d.+/- & 15.08 (s.d.t/- & \\
\hline Marijuana & 75.4 & 79.6 & $5.235)$ & $3.849)$ & \\
\hline & & & 20.73 (s.d.+/- & & \\
\hline Cocaine & 2.2 & 1.1 & 5.587) & 1 & 17 \\
\hline & & & 24.63 (s.d.+/- & & \\
\hline Crack & 1.6 & 0 & 5.587) & & 0 \\
\hline & & & 34.50 (s.d.+/- & & \\
\hline Heroin & 0.4 & 0 & 7.778) & & 0 \\
\hline & & & 10.00 (s.d.+/- & & \\
\hline Inhalant & 0.4 & 0 & 4.243) & & 0 \\
\hline & & & 17.06 (s.d.+/- & 15.94 (s.d.+/- & \\
\hline Tobacco & 68.5 & 74.2 & 7.096) & $5.319)$ & \\
\hline & & & 16.06 (s.d.+/- & 15.87 (s.d.+/- & \\
\hline Alcohol & 78.3 & 80.4 & $5.635)$ & 4.462) & \\
\hline Medication (without & & & 25.33 (s.d.+/- & & \\
\hline prescription) & 0.5 & 1.1 & 4.041) & & 0 \\
\hline & & & 22.20 (s.d.+/- & & \\
\hline Other & 0.9 & 0 & $5.020)$ & & 0 \\
\hline
\end{tabular}




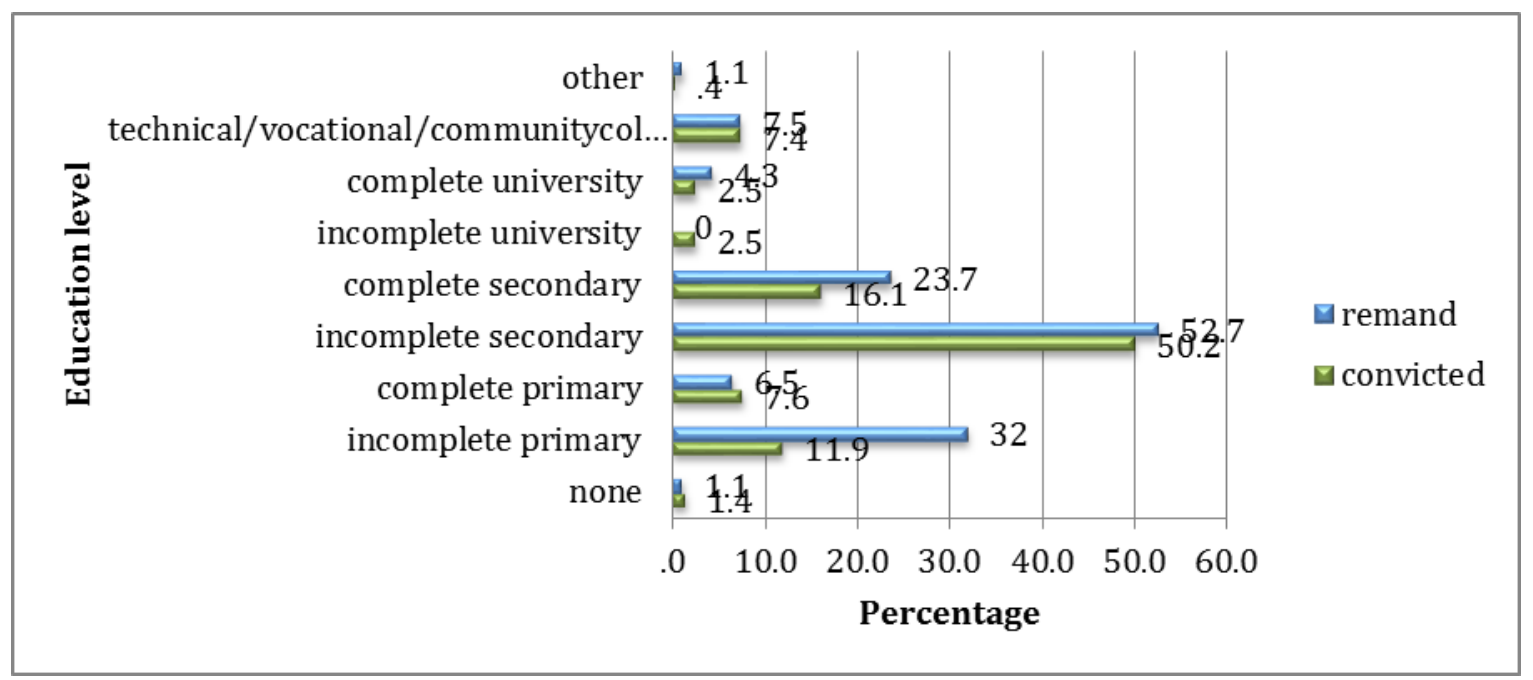

Fig 1: Education level in percentage

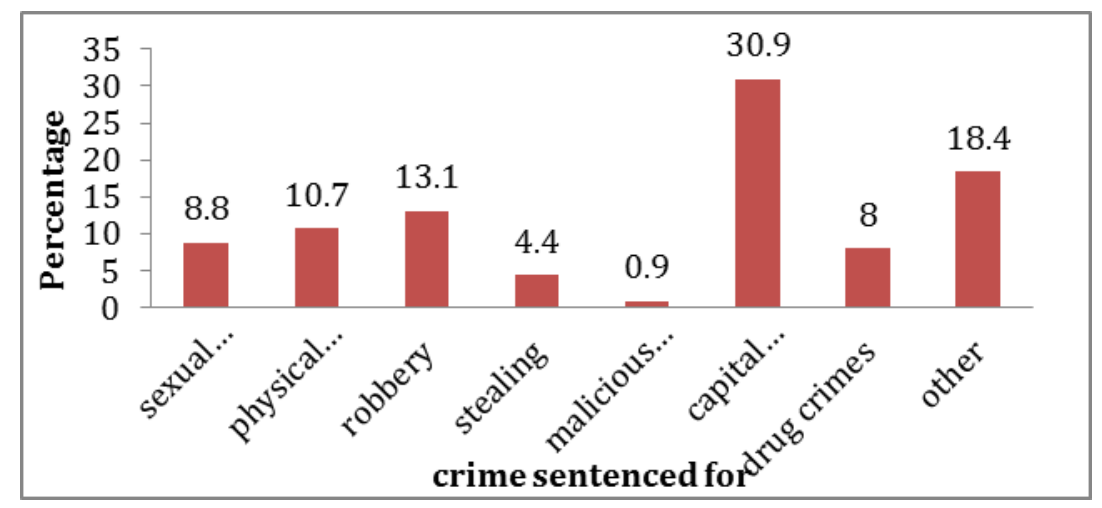

Fig 2: Offence category of convicted inmates in percentage 